\title{
The More Eccentric the Idea, the Better for MRS
}

Recently I had the opportunity to read the letters of the English philosopher and economist John Stuart Mill (1806-1873). As I begin a year as President of the Materials Research Society, two of his quotations seem to resonate:

\section{"All good things which exist are the fruits of originality."}

and

"That so few now dare to be eccentric marks the chief danger of our time."

It is appropriate that MRS should examine itself in the context of both of these statements.

The applicability of the first quotation to MRS is obvious. In a period when materials research has become internationally recognized as one of the most enabling of technological activities, MRS stands out as the premier materials society which programs, publishes, and carries out other professional activities in truly original ways. The structure of the Spring and Fall Meetings, with different groups of meeting chairs reinventing the program twice each year, allows and even demands originality in the knowledge development the Society offers its members. At the same time, major publications of the Society-the Journal of Materials Research, the MRS Bulletin, and more than 500 Proceedings Volumes-capture the overwhelmingly interdisciplinary and multidisciplinary spirit and character of

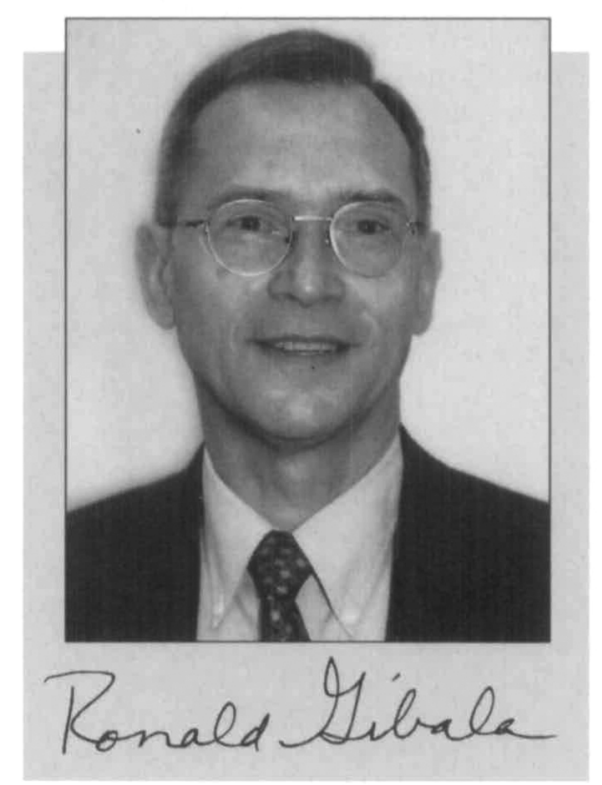

research reported regularly at the meetings. To complement the excellence of the programs and publications, the basic committee structure of MRS is constantly evolving and strives to be inclusive in the goal to seek out original approaches toward supplying member needs. These approaches include electronic publishing on the MRS website of rapidly evolving news items and technologies such as the MIJ-NSR Nitride Journal.

Yet, perhaps the biggest danger to the remarkable success which MRS originality has engendered is the success itself. The Society must continue to reinvent itself, to dare to be different, and to flirt with failure on new, exciting, and indeed eccentric ventures. The second quotation by Mill must be taken as a challenge, lest it become hauntingly applicable to activities in years to come.

In broad terms, MRS must become even more dynamic and responsive to the newest developments in materials research. It must welcome all materials researchers to participate in ever-evolving types of programming and provide professional identity and services that will enable members throughout their careers. It must lead the world by having an international perspective in all of its activities, developing strategic alliances with other materials societies, and providing outreach on materials issues to the general public and leaders of society.

The paths by which MRS achieves such goals must come from member ideas. In later articles, I'll share some of the ideas being developed in the MRS Executive Committee and Council. What would you like to see MRS do? And in what ways would you like to participate? Please let me know, either directly by e-mail, phone, or fax or through the MRS Headquarters at 506 Keystone Drive, Warrendale, PA 15086-7573; 724-779-3003; fax 724-7798313. In the spirit of Mill, the more eccentric the ideas, the better.

Ron GibalaA

1999 MRS President 925-294-4751*

fax 925-294-3410* rgibala@sandia.gov* *Through July 31, 1999

\section{Letters to the Editor}

\section{Additional Information on Emergence of Chalcopyrites as Nonlinear Optical Materials}

\section{To the Editor:}

This is with reference to the overview of the review articlel on chalcopyrites as potential infrared nonlinear crystals. The objective of this letter is to provide some omitted information and additional data as an aid to more effective use of the crystals, as one of the authors (GCB) has been associated with the developments of chal- copyrite crystals for nonlinear optical laser devices since the early 1970s. The first set of nonlinear optical work on these crystals started in the early 1970s almost simultaneously at Southampton University in the United Kingdom and in the United States at Stanford University along with Bell Laboratories. Whereas in Southampton, although a systematic study of a number of chalcopyrite crystals was taken up, only $\mathrm{AgGaS}_{2}$ and $\mathrm{AgGaSe} \mathrm{e}_{2}$ emerged.

While the overview highlighted the developments of chalcopyrites in the
United States (US) and former Soviet Union, the activities in the late 1960s and 1970s in the United Kingdom (UK) and elsewhere are no less important. They have significantly contributed for further developments in optical properties and device applications. ${ }^{2-6}$

Activities in the UK were so motivated that the topic eventually gave birth to a series of International Conference on Ternary and Multinary Compounds (ICTMC), the first of which was held in the University of Bath in 1973 followed by Strasbourg 
(1975), Edinburgh (1977), Tokyo (1980), Cagliari (1982), Caracas (1984), Snowmass (1986), Kishinev (1990), Yokohama (1993), Stuttgart (1995), Salford (1997), and the 12th one is due in 1999 in Taiwan.

Work done at Southampton includes ${ }^{6-8}$ optical transmission range (band-edge and two-phonon cut-off) of a number of I-III- $\mathrm{V}_{2}$ crystals including the weak three-phonon absorption band before the onset of twophonon absorption transmission cut-off and second harmonic generation from $\mathrm{CO}_{2}$ laser. The three-phonon absorption occurs near $9.5 \mu \mathrm{m}$ in $\mathrm{AgGaS}_{2}, 9.5 \mu \mathrm{m}$ in $\mathrm{ZnGeP}_{2}, 14 \mu \mathrm{m}$ in $\mathrm{CdGeAs}_{2}$ and $\mathrm{AgGeS}_{2}$ and can be annoying to a device nonlinear conversion efficiency. The work ${ }^{7}$ also reveals existence of a window beyond the two-phonon cut-off as was later exploited in $\mathrm{AgGaS}_{2}$ by Seymour and Zernike ${ }^{9}$ for a generation of 14-19 $\mu \mathrm{m}$ radiation and also in $\mathrm{LiIO}_{3}$ beyond their nominal transmis$\operatorname{sion}^{10}$ cut-off limit 6.8-7.8 um. The other important study, though not exhaustive, is the postgrowth quality improvement in $\mathrm{AgGaS}_{2}$ which was later done more systematically by Soviet researchers, eventually adopted as a standard technique by crystal growers.

On the question of the so-called unsolved problem of a $\mathrm{CO}_{2}$ laser SHG in $\mathrm{ZnGeP}_{2}$ crystal by Andreev et al., ${ }^{11}$ a departure of $\left(5-10^{\circ}\right)$ smaller experimental phase-matching angle from that of the predicted value, a significant positive temperature coefficient of birefringence in $\mathrm{ZnGeP}$ leads to a decrease in phasematching angle with a rise in temperature. Mainly due to the decrease of phasematching angle with a rise in temperature, the long wavelength phase-matching cutoff is increased. A temperature rise of the crystal by $150-200^{\circ} \mathrm{C}$ (per our reported ${ }^{12}$ temperature-dependent Sellmeier) leads to a decrease in phase-matching angle by $6^{\circ}$. It is possible that the crystal is heated up while it is irradiated even for a few minutes with a $\mathrm{CO}_{2}$ laser radiation through its residual absorption. This cumulative absorption is sufficient to raise the temperature of the crystal by about $150^{\circ} \mathrm{C}$ as has been verified by experiment with our original old Soviet crystal. The old Soviet crystal of several $\mathrm{mm}$ thick has a significant residual absorption and while it is being irradiated with several watts of continuouswave $\mathrm{CO}_{2}$ laser radiation, it experiences also an additional absorption near the $9.5 \mathrm{~m}$ region due to three-phonon absorption. In fact in our earlier experiment, use of a heater is hardly needed while studying temperature-dependent $\mathrm{SHG}$ with a $\mathrm{CO}_{2}$ laser. The increase in discrepancy near the noncritical point is associated with an increase in phase-matched acceptance angle as large as $10^{\circ}$ as one approaches the noncritical phase-matching angle.

On the question of mixed chalcopyrite crystals, although due importance is attached to our pioneering work ${ }^{14,15}$ in $\mathrm{AgGa}_{1-x} \mathrm{In}_{x} \mathrm{Se}_{2}$ crystal for near-noncritical SHG with $\mathrm{CO}_{2}$ laser, other crystals of importance have been left out. Here, in addition to increase in conversion efficiency and realization of noncritical phase matching (NCPM) for SHG over AgGaSe crystal, NCPM for THG for $\mathrm{CO}_{2}$ laser radiation has since also been reported. ${ }^{16}$ The other mixed crystal of importance for which preliminary work has been reported $^{17,21}$ and not covered in the July 1998 issue of MRS Bulletin are $\mathrm{AgGa}_{1-x} \mathrm{In}_{x} \mathrm{Se}_{2}$ $\mathrm{AgGa}\left(\mathrm{S}_{x} \mathrm{Se}_{1-x}\right)_{2}$ and $\mathrm{CdGe}\left(\mathrm{P}_{x} \mathrm{As}_{1-x}\right)_{2}$. Out of these only the first one with some consideration offers the possibility of NCPM with $\mathrm{CO}_{2}$ laser $\mathrm{SHG}$ as the birefringence of $\mathrm{AgInS} \mathrm{S}_{2}$ is nearly zero. The $\mathrm{AgGa}\left(\mathrm{S}_{x} \mathrm{Se}_{1-x}\right)_{2}$ crystal does not offer this possibility of NCPM for $\mathrm{CO}_{2}$ laser SHG due to considerable birefringence. The $\mathrm{CdGe}\left(\mathrm{P}_{x} \mathrm{As}_{1-x}\right)_{2}$ crystal being positively birefringent is not so promising. One more member in this category belonging to the defect tetrahedral group is $\mathrm{Cd}_{x} \mathrm{Hg}_{1-x} \mathrm{Ga}_{2} \mathrm{~S}_{4}$ for which some work has been reported by researchers from the former Soviet Union, including noncritically phase-matched infrared up-conversion detection. This can be even more promising as $\mathrm{HgGa}_{2} \mathrm{~S}_{4}$, as a well-studied crystal, is characterized by a high laser damage threshold and the crystal transmits well into the visible region like AgGaS ${ }_{2}$. The birefringent of the other end crystal, $\mathrm{CdGa}_{2} \mathrm{~S}_{4}$, is too small to allow phase matching, thereby there exists a distinct possibility for noncritical phase matching in a certain composition.

\section{References}

1. M.C. Ohmer and R. Pandey, MRS Bull. 23 (7) (1998).

2. M.V. Hobden, Nature 216 (1967) p. 678.

3. W.N. Honeyman and K.H. Wilkmson,

J. Phys. D: Appl. Phys. 4 (1971) p. 1182.

4. S. Isomura and K. Masumoto, Phys.

Stat. Sol. (a) 6 K (1971) p. 139.

5. V.M. Cound, P.H. Davies, K.F. Hulme, and D. Robertson, J. Phys. D 4 L (1971) p. 83. 6. D.S. Chemla, P.J. Mupeck, D.S. Robertson, and R.C. Smith, Opt. Commun. 3 (1971) p. 29. 7. G.C. Bhar and R.C. Smith, Phys. Stat.

Sol. (a) 13 (1972) p. 157.

8. G.C. Bhar and R.C. Smith, IEEE J. Quan.

Electron. QE-14 (1974) p. 546.

9. R.J. Seymour and F. Zernike, Appl.

Phys. Lett. 29 (1976) p. 705.

10. G.C. Bhar, U. Chatterjee, and A.M. Rudra, Appl. Phys. B 60 (1995) p. 489.

11. Yu. M. Andreev et al., Sov. J. Quan. Electron. 14 (1984) p. 1021.
12. G.C. Bhar, G.C. Ghosh, IEEE J. Quan. Electron. QE-16 (1980) p. 838.

13. G.C. Bhar, S. Das, U. Chatterjee, and K. Vodopyanov, Appl. Phys. Lett. 54 (1989) p. 313.

14. G.C. Bhar, S. Das, U. Chatterjee, P.K. Datta, and Yu. M. Andreev, Appl. Phys. Lett. 63 (1993) p. 1316.

15. G.C. Bhar, S. Das, V.N. Satyanarayana, P.K. Datta, U. Nundy, and Yu. M.

Andreev, Opts. Lett. 20 (1995) p. 2057.

16. G.C. Catella and D. Burlage, MRS Bull. 23 (7) (1998) p. 28.

17. V.V. Badikov et al., Sov. J. Quan Electron. 10 (1980) p. 1302.

18. J.C. Mikkelson and H. Kildal, J. Appl.

Phys. 49 (1978) p. 426.

19. V.V. Badikov et al., Sov. Phys. Crystallgr. 26 (1981) p. 304.

20. V.V. Badikov et al., Sov. J. Quan. Electron. 10 (1980) p. 1300.

21. S.A. Andreev, N.P. Andreev, V.V.

Badikov, E.N. Matveev, and S.M.

Pshenichnikov, Proc. Xth All Union Conference of Coherence and Nonlinear Optics, Kiev (1980) p. 60.

$$
\begin{array}{r}
\text { G.C. Bhar and P. Kumbhakar } \\
\text { Burdwan University } \\
\text { West Bengal, India }
\end{array}
$$

\section{Response}

We are well aware of Dr. Bhar's excellent work on mixed chalcopyrite crystals and temperature tuning. We have also found his papers reporting Sellmeier expressions for the indices of these materials very useful.

We disagree with Dr. Bhar's comment regarding the resolution of the unsolved problem of the phase matching angle discrepancy for the case of $\mathrm{CO}_{2} \mathrm{SHG}$ in $\mathrm{ZnGeP}$. We and our colleagues have carefully investigated this phenomenon. As a result, we are in a position to discard a number of the previous explanations as well as Bhar's speculation concerning this interesting anomaly.

Boyd ${ }^{1}$ stated on the basis of index measurements that $\mathrm{ZnGeP}{ }_{2}$ could not phase match beyond $10.4 \mu \mathrm{m}$. Subsequently, Andreev et al. ${ }^{2}$ determined experimentally that $\mathrm{ZnGeP}_{2}$ will phase match to beyond $11 \mu \mathrm{m}$. Just as importantly, he found that the angle for wavelengths between 9 and $11 \mu \mathrm{m}$ are significantly smaller than predicted. For the case of $10.3 \mu \mathrm{m}$, the predicted angle is $86.4^{\circ}$ and the observed value is $74.3^{\circ}$. They speculated that this lower value was observed because the actual room temperature birefringence of $\mathrm{ZnGeP}$ is significantly larger than Boyd's data indicates. Members of our research team have confirmed Andreev et al.' $\mathrm{s}^{2}$ tuning angle results. ${ }^{3,4}$ Subsequently, Fischer and 
Ohmer 5,6 directly measured the birefringence of $\mathrm{ZnGeP}_{2}$. This work invalidated the speculation of Andreev et al. ${ }^{7}$ and reestablished the phase angle anomaly.

In the same paper Andreev et al. ${ }^{2}$ report that heating the sample to 160 $180^{\circ} \mathrm{C}$ produces a broad maximum in conversion efficiency due to an increasing birefringence with increasing temperature. They clearly reject Bhar's conjecture of a rise in temperature as the source of the anomalously low phase matching angle at room temperature. The results of $\mathrm{CO}_{2}$ SHG experiments performed by Schunemann ${ }^{4}$ at $77 \mathrm{~K}$ (liquid nitrogen temperature) are in even more remarkable disagreement with predictions and Bhar's speculation. Schunemann found that the SHG at $77 \mathrm{~K}$ was twice as efficient. The angle was $63.6^{\circ}$ for $9.3 \mu \mathrm{m}$, only $2.3^{\circ}$ larger than the room temperature value. Even at a temperature of $-196^{\circ} \mathrm{C}$, the angle is still $2.9^{\circ}$ below the predicted room temperature value of $65.5^{\circ}$.

One possible source of the anomaly may be nonlinear absorption effects. SHG experiments in $\mathrm{Te}^{7}$ and $\mathrm{CdGeAs}_{2}{ }^{8}$ indicate that the best performance occurs at angles slightly off of the phasematching angle. In these works, time resolved pulse shape measurements clearly indicate that performance saturates due to an interac- tion between the second harmonic and photo-induced free carriers. The same situation should exist for $\mathrm{ZnGeP}_{2}$.

\section{References}

1. G.D. Boyd, E. Buehler, and F.G. Storz, Appl. Phys. Lett. 18 (1971) p. 301.

2.Yu.M. Andreev, V.G. Voevodin, A.I. Gribenyukov, O.Ya. Zyryanov, I. I. Ippolitov, A.N. Morozov, A.V.Sosin, and G.S. Khmel'nitshii, Sov. J. Quantum Electron. 14 (1984) p. 1021.

3. H.M. Hobgood, T. Henningsen, R.N. Thomas, R.H. Hopkins, M.C. Ohmer, W.C. Mitchel, D.W. Fischer, and S.M. Hegde, J. Appl. Phys. 73 (1993) p. 4030. 4. P.G. Schunemann, Private

Communication.

5. D.W. Fischer, M.C. Ohmer, P.G. Schunemann, and T.M. Pollak, J. Appl. Phys. 77 (1995) p. 5942.

6. D.W. Fischer, M.C. Ohmer, J. Appl.

Phys. 81 (1997) p. 425.

7. W.B. Gandrud and R.L. Abrams, Appl. Phy. Lett. 17 (1970) p. 302.

8. H. Kildal and J.C. Mikkelsen, Opt.

Commun. 10 (1974) p. 306.0

Melvin C. Ohmer

Air Force Research Laboratory Ravindra Pandey

Michigan Technological University

\section{RESEARCH/RESEARCHERS}

\section{Alicyclic Polymers Designed for 193-nm Wavelength Resist Applications}

Photoresist compositions designed for 193-nm lithography by scientists from the Department of Chemistry and Biochemistry at the University of Texas-Austin were fabricated from a series of cycloaliphatic co- and terpolymers of carbo-tertbutoxynorbornene, norbornene carboxylic acid, methyltetracyclododecene carboxylic acid, 5-norbornene-2-methanol, and maleic anhydride, which were synthesize by free radical, $\mathrm{Pd}(\mathrm{II})$-catalyzed addition and ring-opening metathesis polymerization (ROMP) techniques. The purpose of developing lithographic technologies with reduction in exposure wavelengths is to continue to provide higher resolution. While 193-nm lens systems have been developed, the damage threshold for the glass limits the exposure power that can be delivered to the wafer, so highly sensitive resists are necessary to enable 193-nm imaging technology. According to a report published in the November 1998 issue of Chemistry of Materials, the scien- tists at Texas have demonstrated resists with high sensitivities of $3-15 \mathrm{~mJ} / \mathrm{cm}^{2}$ with $0.16 \mu \mathrm{m}$ features resolved.

The resist solutions were spin-coated at $2500 \mathrm{rpm}$ to produce $\sim 0.7-\mu \mathrm{m}$ thick films on 8 in. double-polished silicon wafers. Following exposure to doses ranging from 0 to $50 \mathrm{~mJ} / \mathrm{cm}^{2}$ on a $248-\mathrm{nm}$ or $193-\mathrm{nm}$ excimer laser stepper, the wafer was baked for $60 \mathrm{~s}$ at $150^{\circ} \mathrm{C}$ with postexposure bake temperatures of 140,130 , and $120^{\circ} \mathrm{C}$.

Lithographic evaluation shows that resists formulated with poly(CBN-coNBCA) experienced cracking and adhesion problems; specifically features with dimensions below $0.6 \mu \mathrm{m}$ lose adhesion to the substrate. The scientists conclude that resists made from free radical polymers containing maleic anhydride units show the best resolution and adhesion; those made from Pd(II)-catalyzed addition polymerization suffer from adhesion problems; and resists formulated from ROMP-derived polymers have poor resolution and suffer from phase incompatibility with conventional onium-based photoacid generators.

\section{S $\quad T \quad A \quad I \quad B$ INSTRUMENTS}

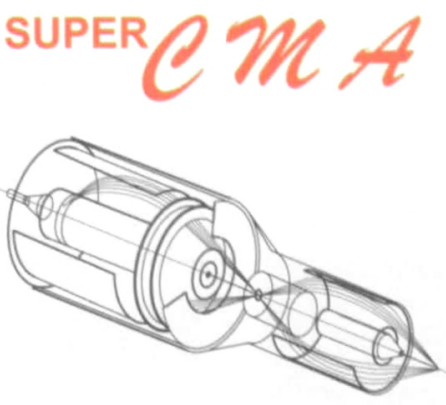

The New Generation

\section{small system, SUPER Features}

combined analyses of AES, SAM, XPS, UPS, ELS, ISS

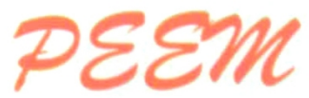

Photo Emission Electron Microscope

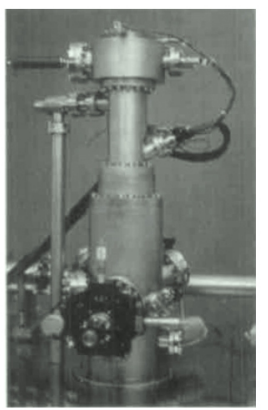

* modular design

* energy filtering

* photoelectron spectroscopy

* chemical imaging

* high spatial resolution

Other products:
electron guns
RHEED
energy analyzer
ion sources

$\begin{array}{llll}\text { US: } & & & \\ \text { Phone: } & 7578730099 \quad \text { Fax: } 7578730130\end{array}$ e-mail: staib-us@staib-instruments.com

EUROPE / ASIA

Phone: +49234704850 Fax: +49234702751

e-mail sales@staib-instruments.com

\section{www.staib-instruments.com}

Circle No. 5 on Reader Service Card. 